$9^{\text {th }}$ International Workshop on Innovative Simulation for Healthcare

$17^{\text {th }}$ International Multidisciplinary Modeling \& Simulation Multiconference

ISSN 2724-0371 ISBN 978-88-85741-50-8 (C) 2020 The Authors.

DOI: $10.46354 /$ i3m.2020.iwish.001

\title{
Management in the Prevention of Psychosocial Risks in the Technological University of Cotopaxi
}

\author{
Rommel Velastegui ${ }^{1,}{ }^{*}$, Paúl Pullas ${ }^{1}$, Elizabeth Velastegui ${ }^{1}$, Isabel Pullas Tapia ${ }^{2}$ \\ ${ }^{1}$ Universidad Técnica de Ambato, Av. Chasquis and Rio Payamino, Ambato, 180103, Ecuador \\ ${ }^{2}$ Universidad Católica del Ecuador, Av. 12 de October 1076, Quito, 170143, Ecuador \\ *Corresponding author. Email address: rs.velastegui@uta.edu.ec
}

\begin{abstract}
Risk factors such as work stress, monotony, double presence, excessive workload generate interest towards workers welfare. The academic demand and rigorousness are high for teachers in Ecuadorian universities. The objective of this research is to determine risk factors in teachers. The evaluation methodology applied is based on the Ministry of Labor test, structured in 8 dimensions with 58 questions, the population included 79 teachers from the University of Cotopaxi (Ecuador). The type of study is correlational, the methodology presents the following results: (i) Database; (ii) Results of psychosocial risks and (iii) solution strategies. It is concluded that: distress happens in men and women equally; there is a high risk in "Workload and pace" $51 \%$, "Recovery" 51\% and "Workplace harassment" 22\%, which result in physical and psychological imbalance, decreasing productivity and generating work distress.
\end{abstract}

Keywords: Risk factors, Occupational psychology

\section{Introduction}

Currently, work activities have undergone an obvious transformation, due to the variety of input, diversity of information, multiple processes or parallel tasks to be fulfilled at the same time, continuous updating of information, short periods for task fulfillment, and other negative aspects that generate confusion among employees. (Monje Amor, Abeal Vázquez, \& Faína, 2020).

To fulfill these processes on time and avoid being affected by psychosocial risks, employees must be well trained and mentally prepared for radical changes in short periods of time considering that companies focus on optimizing resources. (Sheehana, Garavan, \& Morley, 2020).

In most of the organizations in Ecuador, the transformational leadership that leaders possess generates risk factors in employees such as work stress, monotony, double presence, work overload and others (Gupta, Sarkar, \& Kumar, 2019).

Until not long ago, talking about psychosocial risks was a concealed topic that was not considered in organizations; the assessment of work stress, overwork and other risk factors are elements that have been delved into in the suggested study (Clinton, Conway, Sturges, \& Hewett, 2020).

The first symptom of these risk factors may be poor work performance; they can promptly affect employees' health, the initial symptoms in most cases are not noticeable; however, over time they can become chronic and cause serious health problems. (Metzler, Groeling-Müller, \& Bellingrath, 2019 ).

Several studies mention that occupational health and safety management systems are gaining importance; however, for psychosocial risks, evaluation processes are only briefly mentioned and

(C) 2020 The Authors. This article is an open access article distributed under the terms and conditions of the Creative Commons Attribution (CC BY-NC-ND) license (https://creativecommons.org/licenses/by-nc-nd/4.0/). 
the necessary importance is not given. (Hohnen \& Hasle, 2018).

For this reason, several organizations concerned with the well-being of workers have proposed psychosocial risk assessment methodologies with questionnaires such as the Fpsico, the German Copenhagen, ISTAS 21 and others (Metzler, GroelingMüller, \& Bellingrath, 2019).

In the case of Ecuador, through the Ministry of Labor (MT) in June 2017, it was proposed a psychosocial risk analysis methodology through an assessment questionnaire consisting of 8 study dimensions, which can be applied to any type of company.

This psychosocial risk assessment technique has been applied to teachers at the Faculty of Human Sciences at the Technical University of Cotopaxi.

Once the results of the process have been shown through the proposed technique, it has been proposed a manual for teachers which includes techniques that reduce the impact that psychosocial risk factors may produce.

\section{State of the art}

Psychosocial risks have particularities, to prevent or control them it is necessary to take them with total seriousness (Coulter, Stephen and Mary, 2014) ignoring the significant occupational risks, long-term meanings known as occupational diseases. The main responsibility lies with the management of the companies to seek the welfare of the collaborator through programs or aircraft implemented in the company.

In organizations, there are events or working conditions that expose the collaborator to degrees of psychosocial risks, multiple activities, timely delivery of work, work overload, inadequate personal relationships and others that can cause negative consequences at the physical, psychological or social level (Boada , 2012).

The activities carried out by the collaborators are exposed to risks even shorter than the long exposure times, which may generate incidents, accidents or occupational diseases. (Arnold, 2012)

\section{Materials and Methods}

\subsection{Population}

In the development of the research, the Technical University of Cotopaxi has been considered as a study unit, specifically the Faculty of Human Sciences as it is the largest and has the largest number of teachers, also due to the good predisposition and interest of the authorities on the research topic.

For data collection and application of the TM psychosocial risk assessment questionnaires, 79 teachers, $100 \%$ of the population, were taken as the study unit; the data has not been intentionally manipulated, it is not an experimental investigation and no sample has been calculated. (Meliá, et al., 2016).

The teachers were previously informed about the application of the questionnaire, being in agreement with the application of the assessment process, the information was collected individually and the data collected is confidential and for academic purposes.

\subsection{Resources for data collection}

There are a number of questionnaires for evaluating psychosocial risks such as: Fpsico, German Copenhagen, ISTAS 21, MT Psychosocial Risk Questionnaire to name a few.

The latter has been chosen for research because it is a new tool approved and validated in Ecuador, it can be used for public and private companies, as well as for operational or administrative activities; that is, it applies according to the characteristics of the institution to be studied. (Ministry of Labor of Ecuador, 2018)

The MT psychosocial risk questionnaire consists of six main parts: (i) General instructions, which is a guide for the respondent; (ii) General data, where sociodemographic questions are found; (iii) Study dimensions, for the evaluation of psychosocial risk factors, which are made up of specific questions on each subject; (iv) Observations and comments, the interviewer must take note of any novelty presented in the development of the survey; (v) Results, indicated by the psychosocial risk assessment technique; and, (vi) Analysis and interpretation of results, which is a guide to diagnose the treatment of the problem which is being studied. (Rodríguez \& Carlotto, 2017).

Deepening the third point: study dimensions, consists of 58 questions, which are measured in 8: D1. Load and work rate, D2. Skills development, D3. Leadership, D4. Range of action and control, D5. Work organization, D6. Recovery, D7. support and D8. Other important points, at the same time subdivided into D8.1. Discriminatory harassment, D8.2. Work harassment, D8.3. Sexual harassment, D8.4. Work addiction, D8.5. Work conditions, D8.6. Double presence, D8.7. Work and emotional stability, D8.8. Self-perceived health (Carpio de los Pinos \& González García, 2017).

\subsection{Criteria for the application of the psychosocial risk factors questionnaire.}

Once the study population has been defined, for the process of applying the psychosocial risk assessment questionnaire to teachers, the following has been considered: (i) voluntary participation; (ii) work time greater than one year. (Cassilde \& Gilson, 2017).

For data collection, a trained occupational risk surveyor was used to provide support in the 
questionnaire application process, and this is support in the event that any questions in the general structure or specific dimension.

\subsection{MT Evaluation methodology}

The MT psychosocial risk assessment test has a Likert rating scale (Summers, Wang, Abd-El-Khalick, \& Said, 2019) represented as follows: disagree $=1$, slightly agree $=2$, partially agree $=3$, completely agree $=4$.

The structure of each dimension is represented by a set of questions and the assessment scale represented in Table 1, which in the end is a partial addition for each dimension.

\begin{tabular}{|c|c|c|c|c|}
\hline D1: Work load and pace (Item) & 4 & 3 & 2 & 1 \\
\hline $\begin{array}{l}\text { I consider that the requests and requirements } \\
\text { that other people ask me are acceptable. }\end{array}$ & & & & $\mathrm{X}$ \\
\hline I decide my own work pace in my activities. & & & $\mathrm{X}$ & \\
\hline $\begin{array}{l}\text { The activities or responsibilities assigned to } \\
\text { me do not cause me stress. }\end{array}$ & & & & $\mathrm{X}$ \\
\hline $\begin{array}{l}\text { I have enough time to carry out all the } \\
\text { activities that have been entrusted to me } \\
\text { within my working day. }\end{array}$ & & & & $\mathrm{X}$ \\
\hline Sum of points of the dimension & 5 & & Po & \\
\hline
\end{tabular}

For the assessment of D1 according to the proposed scale, which consists of four questions, using Table 1 as an example, and referring to the data obtained from the questionnaire, applied to teachers; the scoring is done through the following equation:

$$
\begin{aligned}
& \text { Sum of dimension points }=P_{1}+P_{2}+P_{3}+P_{4} \\
& \text { Sum of dimension points }=1+2+1+1 \\
& \text { Sum of dimension points }=5
\end{aligned}
$$

The 8 dimensions made up of 58 questions are evaluated through this scale; the number of questions that make up each dimension, the maximum value and the minimum value that can be generated as a result of the application of the questionnaire are indicated in Table 2.

Table 2 indicates the 8 dimensions, but also indicates that D8: Other important points, which is made up of 24 questions, D8 is made up of 8 subdivisions and each of these subdivisions is made up of a certain number of questions that added together the subdivisions will give a total of 24 questions from D8.

So far the evaluation methodology of a teacher has been shown, the questionnaire can generate results individually represented by each of the dimensions of psychosocial risk factors.
Table 2. Dimensions, number of questions and highest evaluation.

\begin{tabular}{cccc}
\hline Dimensions & $\begin{array}{c}\text { Number of } \\
\text { questions }\end{array}$ & $\begin{array}{c}\text { Maximum } \\
\text { score }\end{array}$ & $\begin{array}{c}\text { Minimum } \\
\text { score }\end{array}$ \\
\hline D 1. & 4 & 16 & 4 \\
D 2. & 4 & 16 & 4 \\
D 3. & 6 & 24 & 6 \\
D 4. & 4 & 16 & 4 \\
D 5. & 6 & 24 & 6 \\
D 6. & 5 & 20 & 5 \\
D 7. & 5 & 20 & 5 \\
D 8. & 24 & 96 & 24 \\
D 8.1. & 4 & 16 & 4 \\
D 8.2. & 2 & 8 & 2 \\
D 8.3. & 2 & 8 & 2 \\
D 8.4. & 5 & 20 & 5 \\
D 8.5. & 2 & 8 & 2 \\
D 8.6. & 2 & 8 & 2 \\
D 8.7. & 5 & 20 & 5 \\
D 8.8. & 2 & 8 & 2 \\
\hline
\end{tabular}

Once the teachers have been individually assessed, the psychosocial risk factors will give scores for each one of the dimensions, through Low Risk, Medium Risk and High Risk, determined by ranges of assessment indicated in Table 3.

\begin{tabular}{cccc}
\begin{tabular}{c} 
Table 3. Assessment rank according to risk type. \\
\hline $\begin{array}{c}\text { Result by } \\
\text { dimensions }\end{array}$
\end{tabular} & Low risk & Medium risk & High risk \\
\hline D 1. & 13 a 16 & 8 a 12 & 4 a 7 \\
D 2. & 13 a 16 & 8 a 12 & 4 a 7 \\
D 3. & 18 a 24 & 12 a 17 & 6 a 11 \\
D 4. & 13 a 16 & 8 a 12 & 4 a 7 \\
D 5. & 18 a 24 & 12 a 17 & 6 a 11 \\
D 6. & 16 a 20 & 10 a 15 & 5 a 9 \\
D 7. & 16 a 20 & 10 a 15 & 5 a 9 \\
D 8. & 73 a 96 & 49 a 72 & 24 a 48 \\
\hline
\end{tabular}

The overall risk results to which each teacher is exposed to are established in the same way in ranks indicated in Table 4, which is the sum of the scores of all dimensions.

Table 4. Complete rank result of each teacher.

\begin{tabular}{cccc}
\hline \multirow{2}{*}{ Complete result } & Low risk & Medium risk & High risk \\
\cline { 2 - 4 } & 175 a 232 & 117 a 174 & 58 a 116 \\
\hline
\end{tabular}

\subsection{Information consolidation}

Once each of the 79 teachers from the Faculty of Human Sciences of the Technical University of Cotopaxi have been evaluated, the information from each one of them was consolidated to determine in what range of psychosocial risk the institution is. 


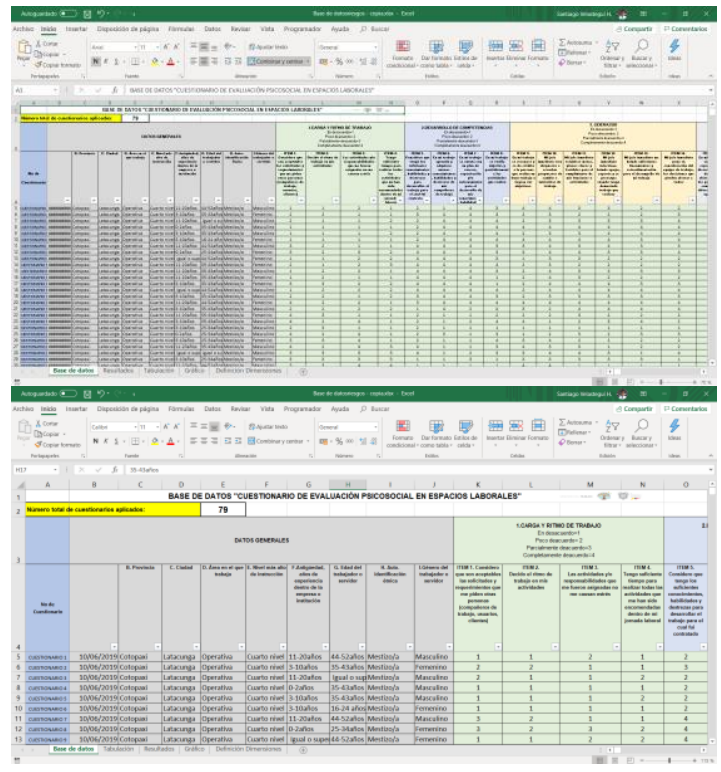

Figure 1. : Excel data validation tool

For the consolidation of the information, an Excel spreadsheet, indicated in Figure 1, was used which is a tool for tabulating information, which contains: (i) Database, is the consolidated information of the 79 physically applied questionnaires and transcribed to the dynamic table "database"; (ii) Tabulation, shows results on the 8 dimensions; it is made up of 58 questions distributed as indicated in Table 2, these results are the sum of the results delimited by the Likert scale; (iii) Results are represented in low risk, medium risk and high risk, the source of information in the "Tabulation" spreadsheet. These results are divided into two parts: 1 . Results by dimensions, which consists of counting the results of each question that makes up the dimension, the evaluation ranges are indicated in Table 3; and, 2. Global results, which performs a general count of the sum of the values obtained in all dimensions, the global result ranges are indicated in Table 4, these results are the percentage of risk that the institution has; (iv) Graph, which didactically shows the results of low risk, medium risk and high risk for each dimension; and, (v) Dimensions definitions, which are indicatiors and technical definitions proposed by the Ministry of Labor's psychosocial risk assessment methodology.

\subsection{Complete results of the psychosocial risk assessment.}

The proposed methodology presents the global results according to the evaluation of the psychosocial risk of teachers, these are divided into three:

1. Low risk, does not generate short-term risk and can be avoided through periodic monitoring of frequency and lowers the probability that an occupational disease may occur.

2. Medium risk, it has a moderate impact, it can affect in the medium term, it causes harmful effects on health, physical integrity and occupational diseases;

3. High risk, the levels of danger are unbearable and can immediately generate harmful effects in people's health and physical integrity. (Airaksinen, Jokela, \& Virtane, 2017).

\subsection{Data analysis in SPSS}

Once the physical surveys have been applied; The 58 questions that contain the questionnaire were transformed into 58 study variables in the SPSS software, this information is indicated in Figure 2.

The following steps have been proposed to process the data: (i) Entering data obtained from the application of the survey to the data tabulation tool provided by the MT; (ii) Data entry to the IBM SPSS Statistics 20 software; (iii) Validation of data through crossover variables (Šonje, 1991).

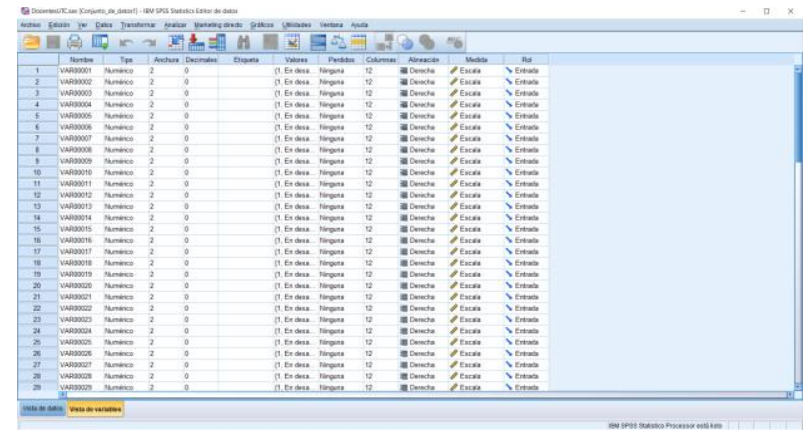

Figure 2. : SPSS research variables.

\subsection{Solution strategies.}

Once the situation regarding psychosocial risk factors of UTC teachers has been diagnosed, strategies have been proposed to reduce their impact through a UTC teachers life quality plan.

The document presented contains 3 core ideas of action: (i) Labor well-being that contains: 1. Medical examinations control schedule. 2.Manual to avoid visual fatigue of the administrative area. 3. Personal Protective Equipment Table; (ii) Interpersonal Relations. (iii) Environment and safety at work.

\section{Results and Discussion}

The results of the questions on sociodemographic data applied to 79 teachers representing $100 \%$ of the study population, of which we have 36 men (44\%) and 43 women (56\%); all have postgrad studies, they are full time teachers; they have experience in education for more than 2 years, as indicated in Table 5 . 
Table 5. Gender of study population.

\begin{tabular}{ccc}
\hline \multirow{2}{*}{ Age range } & \multicolumn{2}{c}{ Gender } \\
\cline { 2 - 3 } & Men & Women \\
\hline 25-34 years & 5 & 7 \\
35-43 years & 17 & 17 \\
44-52 years & 15 & 10 \\
53 or more & 6 & 2 \\
Total & $36(44 \%)$ & $43(56 \%)$ \\
\hline
\end{tabular}

Table 6. Result by dimension of the psychosocial risk assessment.

\begin{tabular}{cccc}
\hline $\begin{array}{c}\text { Questionnaire } \\
\text { dimensions }\end{array}$ & Low risk & Medium risk & High risk \\
\hline D 1. & $10 \%$ & $39 \%$ & $51 \%$ \\
D 2. & $37 \%$ & $44 \%$ & $19 \%$ \\
D 3. & $63 \%$ & $29 \%$ & $8 \%$ \\
D 4. & $53 \%$ & $35 \%$ & $11 \%$ \\
D 5. & $67 \%$ & $27 \%$ & $6 \%$ \\
D 6. & $6 \%$ & $43 \%$ & $51 \%$ \\
D 7. & $54 \%$ & $39 \%$ & $6 \%$ \\
D 8. & $71 \%$ & $27 \%$ & $3 \%$ \\
D 8.1. & $65 \%$ & $34 \%$ & $1 \%$ \\
D 8.2. & $46 \%$ & $33 \%$ & $22 \%$ \\
D 8.3. & $72 \%$ & $20 \%$ & $8 \%$ \\
D 8.4. & $58 \%$ & $37 \%$ & $5 \%$ \\
D 8.5. & $54 \%$ & $30 \%$ & $15 \%$ \\
D 8.6. & $52 \%$ & $41 \%$ & $8 \%$ \\
D 8.7. & $72 \%$ & $25 \%$ & $3 \%$ \\
D 8.8. & $54 \%$ & $35 \%$ & $10 \%$ \\
\hline
\end{tabular}

Table 6 presents the results obtained from the application of the psychosocial risks questionnaire, where the highest risk of highest consideration in dimensions D1 is identified: Workload and work pace $51 \%$, because teachers are subjected to mental overwork for the accomplishment of several activities at the same time in a short period of time. High work load generates as a result physical and psychological imbalance that triggers the decrease in productivity (Pyhältö, Pietarinen, Haverinen, Tikkanen, \& Soini, 2020); D2: Competencies development 19\%, however, competency management tries to balance the needs of teachers with senior managers to achieve a harmonious environment and for the better well-being of all members of the company (Suntheimer \& Wolf, 2020 ); and D6: Recovery 51\%, this problem occurs due to the short amount of time to present reports and results, that is, a teacher does not have enough time to recover from physical and mental tiredness, all these bad habits can trigger physical and psychological illnesses that can alter the well-being of people's health (Cao, Shang, \& Meng, 2020).

Table 7. Overall result of the UTC psychosocial risk assessment.

\begin{tabular}{ccc}
\hline Low risk & Medium risk & High risk \\
\hline $48 \%$ & $51 \%$ & $1 \%$ \\
\hline
\end{tabular}

The overall results of the psychosocial risk assessment for UTC teachers are represented in Table 3; 38 teachers respond to low risk, that is, that the activities, habits and other personal aspects are slightly affected or have a mild impact without being directly sensed the health of the employee. It should be mentioned that any activity that is carried out can generate stress (Cañadas, Mullor, Rodríguez, \& Parón, 2019); 40 teachers respond to medium risk and aspects such as excess of responsibilities, monotony and routine, family and work problems, exhausting work shifts must be considered (Montoya García, Callejón Ferre, Pérez Alons, \& Sánchez Hermosilla, 2013). We must think about the strategic management of human resources to avoid the appearance of these risk factors and consider that the work environment is the main means for employees to properly develop (Teo, Bentley, \& Nguyen, 2019). Finally, with a minimum percentage but which should not be neglected, one high-risk teacher can generate physical and psychological damage if they do not get support (Forstera, L. Amy, Areba, \& J.McMorris, 2019)

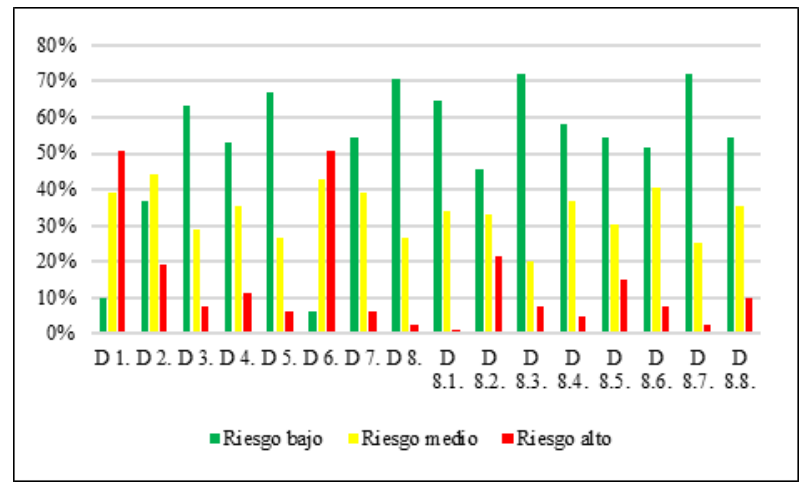

Figure 3. : Result by dimension of the psychosocial risk assessment.

\section{Conclusions}

The general results of psychosocial risks of the study correspond to $48 \%$ low risk, $51 \%$ medium risk and $1 \%$ high risk; However, the intra-occupational psychosocial risks correspond to $26.2 \%$ of the teachers surveyed perceive levels of psychosocial risk for work between medium risk level and high risk level.

From the 8 study dimensions it is obtained that the dimensions where there is a high impact risk are; D1: Workload and Pace with 51\% and D2: Recovery with $51 \%$ affecting the work performance of 40 teachers. In addition, it is necessary to intervene immediately in these dimensions since they are at a level where it can generate harmful effects for the physical health of people, safety and prevention measures must be applied to avoid increasing the probability and frequency.

\section{References}

Airaksinen, J., Jokela, M., \& Virtane, M. (2017). Development and validation of a risk prediction 
model for work disability: multicohort study. Scientific Reports, 1-12.

Cañadas, D. C., Mullor, M. R., Rodríguez, R., \& Parón, T. (2019). Psychosocial risks at work for paediatric health professionals. European Review of Applied Psychology, 5-6.

Cao, C., Shang, L., \& Meng, Q. (2020). Applying the Job Demands-Resources Model to exploring predictors of innovative teaching among university teachers. Teaching and Teacher Education.

Carpio de los Pinos, A. J., \& González García, M. (2017). Critical analysis of risk assessment methods applied to construction works. Revista de la Construcción vol.16 no.1 Santiago abr. 2017.

Cassilde, S., \& Gilson, A. (2017). Psychosocial Health, Work and Language. En S. Cassilde, \& A. Gilson, Psychosocial Health, Work and Language (págs. 93-94). Springer International Publishing.

Clinton , M. E., Conway , N., Sturges , J., \& Hewett, R. (2020). Self-control during daily work activities and work-to-nonwork conflict. Journal of Vocational Behavior, 337-352.

Forstera, M., L.Amy , G., Areba , E., \& J.McMorris, B. (2019). Cumulative psychosocial risks, internal asse, and past 30-day tobacco use among middle and high school students: The promise of internal assets. Addictive Behaviors, 240-247.

Gupta, N., Sarkar, A., \& Kumar, D. (2019). Risk Factors Associated with Onset of Neck Pain: A Review. Indian Journal of Public Health Research \& Development, 356-361.

Hohnen, P., \& Hasle, P. (2018). Third party audits of the psychosocial work environment in occupational health and safety management systems. Safety Science, 76-85.

Meliá, J. L., Nogareda, C., Lahera, M., Duro, A., Peiró, J. M., Salanova, M., \& Gracia, D. (2016). Principios Comunes para la Evaluación de los Riesgos Psicosociales en la Empresa. Perspectivas de intervención en riesgos psicosociales. Evaluación de riesgos, 13-36.

Metzler , Y. A., Groeling-Müller, G., \& Bellingrath, S. (2019). Better safe than sorry: Methods for risk assessment of psychosocial hazards. Safety Science, 122-139.

Ministerio de Trabajo del Ecuador. (23 de 10 de 2018). Ministerio del Trabajo presentó primera herramienta de evaluación de riesgo psicosocial en el país. http://www.trabajo.gob.ec/ministerio-deltrabajo-presento-primera-herramienta-deevaluacion-de-riesgo-psicosocial-en-el-pais/

Monje Amor, A., Abeal Vázquez, J. P., \& Faíña, J. A. (2020). Transformational leadership and work engagement: Exploring the mediating role of structural empowerment. European Management
Journal, 169-178.

Montoya García, M. E., Callejón Ferre , A. J., Pérez Alons, J., \& Sánchez Hermosilla, J. (2013). Assessment of psychosocial risks faced by workers in Almería-type greenhouses, using the Mini Psychosocial Factor method. Applied Ergonomics, 303-311.

Pyhältö, K., Pietarinen, J., Haverinen, K., Tikkanen , L., \& Soini, T. (2020). Teacher burnout profiles and proactive strategies. European Journal of Psychology of Education.

Rodríguez, S., \& Carlotto, M. (2017). Predictors of Burnout Syndrome in psychologists. Estudos de Psicologia (Campinas).

Sheehana , M., Garavan, T. N., \& Morley, M. J. (2020). Transformational leadership and work unit innovation: A dyadic two-wave investigation. Journal of Business Research, 399-412.

Šonje, D. (1991). SPSS/PC+. Vieweg+Teubner Verlag.

Summers, R., Wang, S., Abd-El-Khalick, F., \& Said , Z. (2019). Comparing Likert Scale Functionality Across Culturally and Linguistically Diverse Groups in Science Education Research: an Illustration Using Qatari Students' Responses to an Attitude Toward Science Survey. International Journal of Science and Mathematics Education volume, 885903.

Suntheimer, N. M., \& Wolf, S. (2020). Cumulative risk, teacher-child closeness, executive function and early academic skills in kindergarten children. Journal of School Psychology, 23-37.

Teo , S., Bentley , T., \& Nguyen, D. (2019). Psychosocial work environment, work engagement, and employee commitment: A moderated, mediation mode. International Journal of Hospitality Management. 